Penultimate draft. Please cite published version: doi10.1163/18756735-000022.

\title{
Are Introspective Beliefs about One's Own Visual Experiences Immediate?
}

\author{
Wolfgang Barz \\ Johann Wolfgang Goethe-Universität Frankfurt am Main \\ barz@em.uni-frankfurt.de
}

\begin{abstract}
The aim of this paper is to show that introspective beliefs about one's own current visual experiences are not immediate in the sense that what justifies them does not include other beliefs that the subject in question might possess. My argument will take the following course. First, I explain the notions of immediacy and truth-sufficiency as they are used here. Second, I suggest a test to determine whether a given belief lacks immediacy. Third, I apply this test to a standard case of formation of an introspective belief about one's own current visual experiences and conclude that the belief in question is neither immediate nor truthsufficient. Fourth, I rebut several objections that might be raised against my argument.
\end{abstract}

\section{Keywords}

immediacy - introspective justification - visual experiences - truth-sufficiency

\section{Introduction}

Although there are sharp divisions over the question of how to account for the phenomenon of self-knowledge, most philosophers share the intuition that beliefs about one's current conscious experiences that are achieved by introspective means have an epistemic asset that other empirical beliefs lack. However, it is controversial exactly which epistemic asset this is. 
The traditional view, according to which introspective beliefs about one's current conscious experiences are both infallible and self-intimating, ${ }^{1}$ has been effectively discredited over the past decades - most notably by the work of David Armstrong. ${ }^{2}$ Even the more moderate view according to which introspective beliefs about one's current conscious experiences are indubitable or incorrigible ${ }^{3}$ has come under heavy attack. ${ }^{4}$ However, there is one proposal that has survived the discussion relatively unscathed: in contrast to other empirical beliefs, introspective beliefs about one's current conscious experiences seem to have the epistemic asset of being immediate in the sense that what justifies these beliefs does not include some knowledge or justified belief the subject in question might otherwise possess. ${ }^{5}$ Moreover, it seems that introspective beliefs about one's current conscious experiences are truth-sufficient in the sense that they are justified by the very facts they are about. ${ }^{6}$ Consider, for example, a situation in which you feel pain and, because you feel pain, form the belief "I am in pain now". At the very least, there is a strong inclination to say that the mere fact that you are in pain is sufficient for your being justified in believing that you are in pain. ${ }^{7}$

One might argue that the term "truth-sufficient" does not really capture the idea that it is supposed to express. ${ }^{8}$ Therefore, I would like to add some clarification in order to avoid any misunderstanding. William Alston introduced the idea of truth-sufficiency in order to make a distinction within the class of immediate beliefs - for it might be argued that the feature of being immediate is not exclusive to beliefs about one's current conscious experiences, but is

\footnotetext{
${ }^{1}$ See Hume 1978, 190: "For since all actions and sensations of the mind are known to us by consciousness, they must necessarily appear in every particular what they are, and be what they appear."

${ }^{2}$ See Armstrong 1968, especially 100-115.

${ }^{3}$ See Ayer 1963, 71: "The position I wish to take is that one may be the best authority with regard to one's present thoughts and feelings, even though one's reports of them are not infallible."

${ }^{4}$ The most prominent argument, which is supposed to refute the thesis of indubitability and incorrigibility, is the electroencephalogram argument. For an account of this argument that is still worth reading, see Sheridan 1969.

${ }^{5}$ For this formulation, see Alston 1976, 260. For alternative formulations of the idea of immediacy, see Alston 1971, 233, and 1989a, 58-59.

${ }^{6}$ See Alston 1971, 234; 1976, 262. In the latter passage, Alston uses the term "truth-warrant" instead of "truthsufficiency".

${ }^{7}$ For contemporary advocates of this view, see Neta 2011, Smithies 2012, and Pryor 2014.

${ }^{8}$ As has been pointed out by an anonymous referee of this journal.
} 
also possessed by many perceptual beliefs. For example, it seems reasonable to suppose that what justifies you in believing that there is a fire in your living room fireplace now is not any other belief that you might simultaneously hold. Rather, it is your current sense experience of a fire in your living room fireplace that provides the justification in question. Thus, both beliefs about one's current conscious experiences and perceptual beliefs seem to be immediate in the sense that what justifies them does not include some belief the subject in question might otherwise have. Yet, according to Alston, there is a crucial difference here. Compare the perceptual belief that there is a fire in your living room fireplace with the introspective belief that you are in pain. Whereas it seems reasonable to say that the mere fact that you are in pain suffices to justify your introspective belief, it does not seem reasonable to say that the mere fact that there is a fire in your living room fireplace suffices to justify your perceptual belief. Consider, for example, a situation in which you lack any sense experience of a fire in your living room fireplace (because, say, there is a thick wall between you and the living room). In this case, you would not be justified in believing that there is a fire in your living room fireplace, even though there actually was a fire in your living room fireplace. ${ }^{9}$

Though I admit that the view that introspective beliefs about one's current conscious experiences are both immediate and truth-sufficient has some amount of prima facie plausibility, I believe that, in the final analysis, it does not stand up to scrutiny: there is at least one important subclass of introspective beliefs about one's current conscious experiences, namely introspective beliefs about one's own current visual experiences, that are neither immediate nor truth-sufficient. Rather, the justification of introspective beliefs about one's own current visual experiences depends on other beliefs the subject in question holds. Thus, merely having a particular visual experience is not sufficient to justify holding an introspective belief about that experience. This, at least, is what I will argue in this paper.

\footnotetext{
${ }^{9}$ See Alston 1971, 234.
} 
My argument will take the following course. First, I develop an "immediacy test", that is, a test to determine whether a given belief is dependent for its justification upon other beliefs (section 2). Then, I will apply this test to a situation in which a person forms an introspective belief about his/her own current visual experience under normal conditions (section 3). It will emerge that the justification of this belief stands and falls with a certain perceptual belief that the person holds - and, thus, that the introspective belief in question is neither immediate nor truth-sufficient (section 4). Finally, I address some potential misunderstandings of my argument and rebut several objections that might be raised (section 5).

Before I turn to the immediacy test, allow me to briefly explain the more general philosophical motivation behind this paper. My aim here is not so much to nourish the suspicion that introspective access to one's own current conscious experiences is not privileged or that there is no epistemic asset at all that distinguishes introspective beliefs about one's own current conscious experiences from other empirical beliefs. Rather, my aim is to bolster a particular view about the procedure by which one gains knowledge about one's own current visual experiences, a view that often comes under the label of "transparency". According to this view, one comes to know that one currently has such-and-such a visual experience, not by peering inward at intrinsic features of one's experience, but by focusing instead on those seemingly external objects that one is visually aware of in virtue of having the visual experience in question. ${ }^{10}$ If a view along these lines, as I am inclined to think, is correct, then introspective beliefs about one's own current visual experiences cannot be immediate-for the "transparency" view implies that the acquisition of introspective knowledge about one's own visual experiences is essentially tied to the formation of perceptual beliefs about one's environment.

\footnotetext{
${ }^{10}$ See Byrne 2005, 2011a, 2011b, 2012, Dretske 1995, Evans 1982, Fernandez 2003, 2013, Gallois 1996, Gordon 1996, Moran 2001, Tye 1995 - to name but a few proponents of the transparency view.
} 
In order to forestall possible misunderstandings, allow me to add that I will neither argue for nor presuppose the correctness of the transparency view in what follows. My focus in this paper is entirely on the issue of whether introspective beliefs about one's own current visual experiences are immediate and truth-sufficient, not on the issue of how the procedure by which we obtain knowledge about our own current conscious experiences might be best described. So consider the remarks at hand just as an off-the-record presentation of my philosophical motivation, not as an essential part of my argument.

\section{The immediacy test}

In this section, I present a test by means of which one may assess whether a given belief is immediate. The basic idea is that a given justified belief $A$ cannot qualify as immediate unless it remains justified over counterfactual situations in which some other belief $B$ that the subject actually holds is removed. Consequently, I suggest the following diagnostic question:

(DQ) Does $S$ actually hold a belief $B$ (different from $A$ ) such that, if $S$ did not hold $B$, then $S$ would, other things being equal, not be justified in holding $A$ ?

If the answer to (DQ) is affirmative, then it seems reasonable to conclude that $A$ depends on $B$ for its justification and that, for this reason, $A$ is not immediate.

Notice that, in order for the immediacy test to work, the ceteris paribus clause is indispensable. Suppose that $S$ justifiably believes that $p$. Moreover, suppose for the sake of argument that $S$ 's belief is immediate, that is, $S$ 's belief is justified in virtue of a certain item $j$ that, albeit not a belief itself, confers justification upon $S$ 's belief that $p$. This non-doxastic 
justifier $j$, in turn, is caused by another belief that $S$ holds, namely, the belief that $q$. However, this latter belief - the belief that $q$ - has no bearing on the justification of the belief that $p$. Now, if the immediacy test is applied without care, it is easy to obtain the wrong result. One might say, for example, that there is a different belief $B$ (namely, the belief that $q$ ) such that, if $S$ did not hold it, she would not be justified in believing that $p$ - for if the belief that $q$ did not exist, the non-doxastic justifier $j$ would not exist either; and if $j$ did not exist, the belief that $p$ would not be justified. Thus, even though $S$ 's belief that $p$ is immediate, the immediacy test yields the result that $S$ 's belief that $p$ is not immediate. However, this does not demonstrate that my immediacy test is defective, but that it has not been properly applied: the ceteris paribus clause was simply ignored.

Thus, a proper application of the immediacy test requires us to envisage a counterfactual situation in which the belief that is supposed to have a bearing on the target belief in question is absent, while other things remain constant. For the case at hand, this means that one has to imagine a situation in which (i) $S$ believes that $p$, (ii) item $j$ is present, and (iii) $S$ does not believe that $q$-and then ask, with respect to this situation, whether $S$ 's belief that $p$ is still justified. In order to apply the immediacy test properly, then, one has to sever the causal relation between the belief that $q$ and item $j$. Under these circumstances, the test yields the correct result: even if $S$ did not hold the belief that $q$, she would still be justified in believing that $p$. Of course, this may not show that $S$ 's belief that $p$ is immediate in one stroke (for, besides the belief that $q$, there might be other beliefs — not tested yet — that may have a bearing on the justification of $S$ 's belief that $p$ ), but it does show that the belief that $q$ does not have any bearing on the justification of $S$ 's belief that $p$.

It might be objected that the immediacy test as suggested here is methodologically flawed. The test, it might be said, requires us to check for immediacy by an appeal to our ordinary intuitions about justification. This seems odd because our ordinary intuitions about 
justification cannot be expected to line up with the notion of immediacy. Recall that the latter notion is a technical one, defined by philosophers for philosophical purposes, whereas the notion of justification is a non-technical one. At least, it is less technical than the notion of immediacy in that it stems from ordinary discourse. ${ }^{11}$

In my view, this objection is based on a twofold misconception. First, it may be true that the notion of immediacy is more technical than the notion of justification in that it is defined as "being justified independently of any belief the subject in question might otherwise have". However, note that the main ingredient of this definition is the usual notion of justification that might well be assessed by our ordinary intuitions. Second, it is not quite true that the test requires us to check for immediacy by an appeal to our ordinary intuitions about justification. Note that the test does not require us to evaluate whether a given belief is immediate at all. The only thing that the test requires us to do is, first, to imagine a counterfactual situation in which a subject has a particular belief and, then, to evaluate whether this belief is justified measured against our ordinary standards of justification. ${ }^{12}$

\section{Applying the immediacy test}

Imagine a non-colorblind and conceptually well-equipped person-let us call her MaryAnn — who looks at a red object of medium height under favorable perceptual conditions: the scene is bathed in daylight, the red object is clearly visible, and the light reflected by it triggers an operation of Mary-Ann's visual system which culminates in producing a veridical

\footnotetext{
${ }^{11}$ I owe this objection to an anonymous referee for this journal.

12 This is not to say that the ordinary standards of justification are homogeneous. On the contrary, it seems that the notion of epistemic justification is ambiguous in at least three ways. I will return to this issue in section 4.
} 
visual experience, that is, a visual experience that represents something as being red. ${ }^{13}$ Suppose furthermore that Mary-Ann not only acquires the perceptual belief that there is something red in front of her now, but that she also forms an introspective belief about her own current visual experience to the effect that she currently has a visual experience as if there is something red in front of her. Suppose furthermore again, that Mary-Ann holds a background belief to the effect that perceptual conditions are favorable, that is, she holds the belief that, currently, things are as she experiences them to be. ${ }^{14}$ Let us call Mary-Ann's perceptual belief $\mathfrak{P O}$, her introspective belief $\mathfrak{I}$, her background belief $\mathbf{2} 3$, and the scenario at hand the actual situation, which might be illustrated as follows:
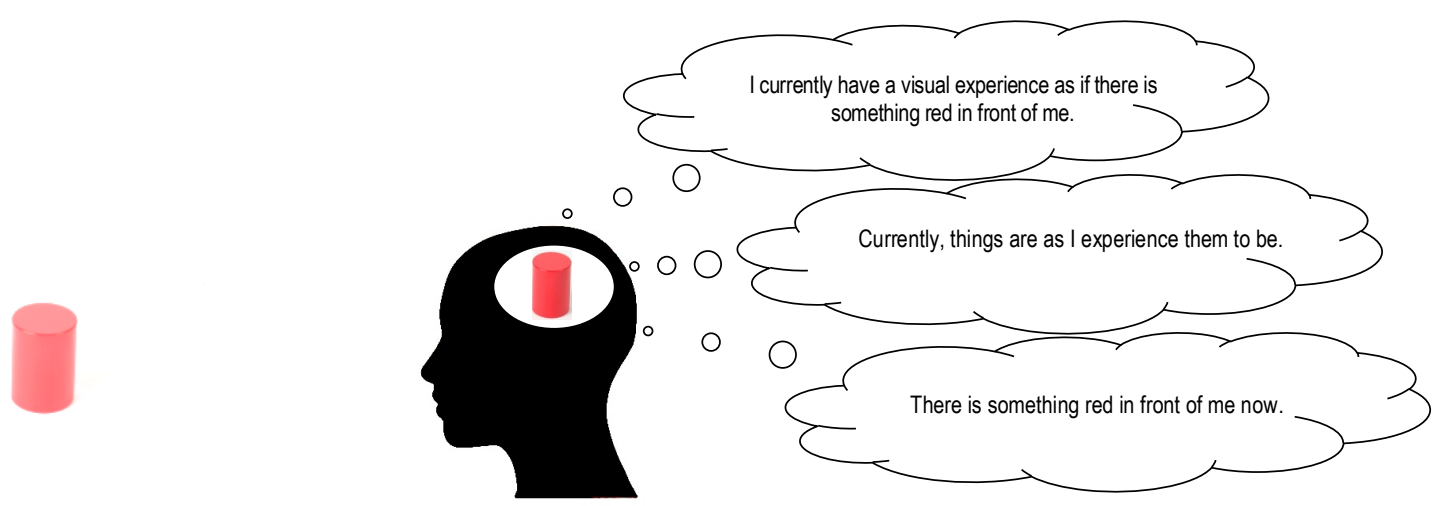

Figure 1

\footnotetext{
${ }^{13}$ In order to exclude irrelevant side issues, I will be silent about the issue of whether (and in what sense) visual content is non-conceptual. For the purpose of my argument, it will suffice to assume that the content of MaryAnn's visual experience might correctly be described by the sentence "There is something red out there". This is not to say that this sentence gives an exhaustive description of Mary Ann's visual content. On the contrary, this assumption is perfectly compatible with the view that Mary-Ann's visual content is more fine-grained than the sentence "There is something red out there" might suggest. Even if Mary-Ann's visual experience were so finegrained that no sentence, however complex, could ever give an exhaustive verbal description of its content, it would remain true that the sentence "There is something red out there" would provide a correct description of at least some portion of this content.

${ }^{14}$ It is understood that "things are as I experience them to be" unfolds to "the objects in my field of view are colored as my experience represents them to be".
} 
In order to examine whether $I$ is immediate or not, let us apply the test that I developed in the previous section: let us ask whether Mary-Ann actually holds a belief $B$ such that, if MaryAnn did not hold $B$, she would, other things being equal, not be justified in holding I. As it will emerge, there is such a belief $B$-namely, $\mathfrak{\nvdash}$.

Imagine a situation which differs from the actual situation only in one respect: Mary-Ann looks at a red object of medium height under favorable perceptual conditions — which implies that she has a normally caused veridical visual experience of the red object in front of herand holds both $\mathfrak{I}$ and $2 \mathfrak{3}$. However, to everyone's surprise, Mary-Ann does not hold $\mathfrak{P}$, that is, she does not believe that there is something red in front of her now. To be sure, this is not to say that she believes the object in her field of view to be of a color other than red. Rather, she lacks any "positive" belief about the color of the object in her field of view. When asked about the color of the object in front of her, for example, she sincerely claims that she has not the slightest idea. Even with the help of the most sophisticated empirical test procedures, we will not be able to unearth from her any belief about the color of the object in front of herexcept for "No idea!" Let us call this scenario the counterfactual situation, which might be illustrated as follows:

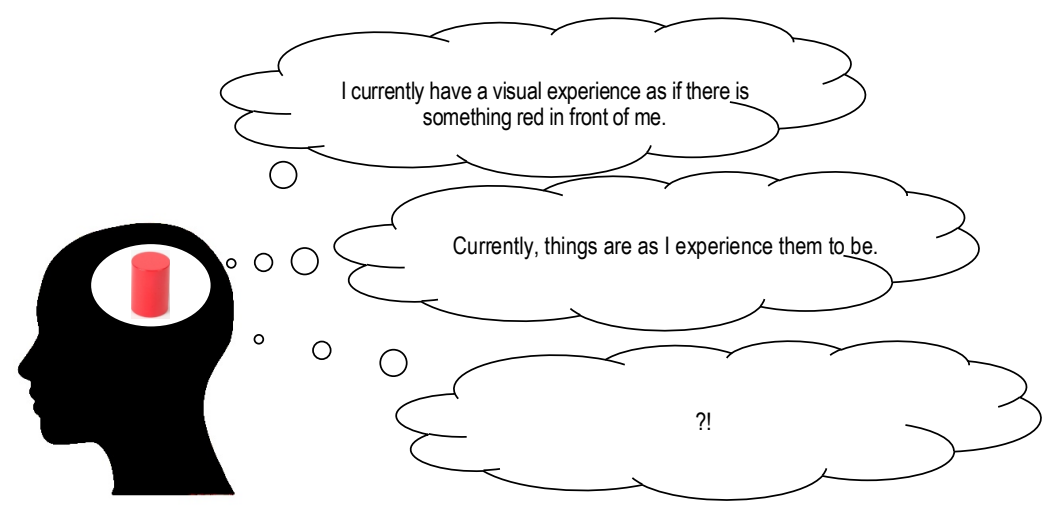

Figure 2 
Now, the crucial question is: is Mary-Ann, in this admittedly strange situation, justified in holding $\mathbf{Z}$, that is, in believing that she currently has a visual experience as if there is something red in front of her? In my view, this question must be answered in the negative. If, in turn, Mary-Ann, in the counterfactual situation, is not justified in holding $\mathfrak{I}$, then $\mathfrak{I}$ is not immediate in the actual situation — for its justification obviously depends on $\mathfrak{\not}$.

\section{Why $I$ is not justified in the counterfactual situation}

In this section, I would like to explain why, in the counterfactual situation, Mary-Ann is not justified in holding I. For this purpose, let me first recall a conceptual truth about visual experiences of the sort that Mary-Ann has, that is, visual experiences that represent something as being red ("visual experiences of red" for short):

For all normally sighted, conceptually well-equipped human beings, visual experiences of red cause perceptual beliefs to the effect that there is something red before one, provided that (a) one's cognitive mechanism responsible for "converting" visual experiences into perceptual beliefs - one's experience/belief transducer, for short—is functioning properly and that (b) one lacks any belief to the effect that the way things are differs from the way one experiences them to be.

If there is a visual experience that does not cause a perceptual belief to the effect that there is something red before one, even though one's experience/belief transducer is functioning properly and one lacks any belief to the effect that the way things are differs from the way one experiences them to be, then this experience cannot be considered a visual experience of red. 
Since Mary-Ann both has a visual experience of red and satisfies condition (b) by hypothesis (recall that she holds $\mathfrak{Z}^{15}$ ), the fact that she does not hold $\mathfrak{P}$ implies that her experience/belief transducer is malfunctioning. Given this diagnosis, $I$ is not justified in the counterfactual situation, no matter how the notion of epistemic justification might be specified, or at least this is what I will argue in the following.

First, let us construe the notion of justification along the lines of what Alston calls the "truthconductivity view". ${ }^{16}$ According to this view, the question of whether a given belief is justified depends on whether the conditions of its production are such that it is likely that the belief in question is true. However, in the counterfactual situation, the conditions of production of $I$ are such that it is not likely that $I$ is true. Recall that Mary-Ann's experience/belief transducer is malfunctioning. In particular, Mary-Ann is momentarily not able to recognize a red object as red $^{17}$ - even though this object is presented to her under favorable perceptual conditions ${ }^{18}$ and even believed by her to be presented under such conditions. However, if one, at a certain time $t$, is not able to recognize a red object as redalthough one perceives this object under favorable perceptual conditions and even believes that perceptual conditions are favorable-, then there is no reasonable chance that, at $t$, one is

\footnotetext{
${ }^{15}$ One might object that lacking any belief to the effect that the way things are differs from the way one experiences them to be does not imply having a belief such as $\mathbf{2}$. Lacking a belief to the effect that the way things are differs from the way one experiences them to be, for example, is compatible with withholding any belief about the relation between appearances and reality. This might be true, but is irrelevant in the present context. The crucial point is that having a belief such as $\mathfrak{Z}$ is incompatible with having a belief to the effect that the way things are differs from the way one experiences them to be.

${ }^{16}$ See Alston 1996, 244.

${ }^{17}$ Of course, there are two relevant senses of "to recognize a red object as red" here. The first is "to have a veridical visual experience", the second is "to form a correct perceptual belief on the basis of one's visual experience". Mary-Ann does recognize the object's color in the first sense, but not in the second.

${ }^{18}$ It might be objected that perceptual conditions are not favorable, because there is a disturbance in Mary-Ann's cognitive system. However, this objection is based on an uncharitable reading of "favorable perceptual conditions". As indicated in the exposition of the Mary-Ann case, I use "favorable perceptual conditions" to refer to the fact that the scene is bathed in daylight, and the red object is clearly visible and triggers an operation of Mary-Ann's visual system which culminates in producing a visual experience representing an object as being red. Thus, by saying that perceptual conditions are favorable, I do not intend to imply that Mary-Ann's cognitive system is functioning properly. The favorability claim, as one might say, covers the causal chain that leads to Mary-Ann's visual experience, but it does not cover the events that take place after the visual experience has been formed.
} 
able to recognize a visual experience of red as a visual experience of red. Surely, in the situation at hand, Mary-Ann does form a correct introspective belief about her current visual experience, $\mathfrak{I}$. However, I contend, the correctness of $\mathfrak{I}$ cannot be due to a successful exercise of her capability to recognize red things as red-for if it is, then it is incomprehensible why Mary-Ann is not able to recognize the red object in front of her as something that is red. In short: $I$ is no more than a lucky guess.

"But why suppose this?" one might object. "Two different pathways are at play here: the one-call it the perceptual pathway-starts at the visual experience and ends at some perceptual belief; the other one-call it the introspective pathway-likewise starts at the visual experience, but ends at some introspective belief. In the counterfactual case of MaryAnn, there is obviously a disturbance in the perceptual pathway. But it is not clear whether a disturbance in the perceptual pathway has any effect on the introspective pathway. On the contrary, it seems that there really is no disturbance in the introspective pathway-for I at least is true. So why not suppose that, apart from the fact that they arise from the same source, the two pathways neither overlap nor intersect? If this were true, the mere fact that Mary-Ann is momentarily not able to recognize a red object as red would not decrease the chance that she is able to recognize a red visual experience as a visual experience that represents something to be red."

I do not think that this objection is cogent. If the two pathways neither overlapped nor intersected after they left their common source, then we would be forced to posit two different color recognition systems: one-call it the noumenal color recognition system-has the function of discovering the color that the object that is visually represented has (provided that the object is presented under favorable perceptual conditions), whereas the other one-call it the phenomenal color recognition system - has the function of discovering the color that the object is visually represented as having (no matter whether the object is presented under 
favorable perceptual conditions or not). Apart from the fact that there is no scientific evidence for two color recognition systems that work independently from each other, the positing of both a noumenal and a phenomenal color recognition system leads to absurd consequences. If there are two independent color recognition systems, then it is possible that the one functions properly and the other one is broken. So assume, for the sake of argument, that, while my noumenal color recognition system functions properly, my phenomenal color recognition system is broken. Thus, when I am confronted with an object under favorable perceptual conditions, I might be able to recognize what color this object is, but not what color the object looks like to me. In my view, this is not even a conceptual possibility. Therefore, the assumption with which we began - that there are two color recognition systems, noumenal and phenomenal, that work independently from each other-must be false. ${ }^{19}$ Thus, it remains true that if one is, at a certain time $t$, unreliable with respect to one's judgments about the color of a given material object, then one is, at $t$, likewise unreliable with respect to one's judgments about the color one's visual experience represents this object as having. I, then, may be true- but if it is true, it is accidentally so. There is nothing about the conditions of its production that make it likely that it is true.

There is still another objection that deserves to be addressed. It might be said that the plausibility of my argument heavily depends on how one conceives the content of visual experiences and, correspondingly, on how one models the content of introspective beliefs about one's current visual experiences. Recall that I have characterized Mary-Ann's visual

\footnotetext{
${ }^{19}$ Notice that the scenario that is outlined in this argument is different from the counterfactual situation of MaryAnn. Therefore, it is not incoherent to claim that, while the counterfactual situation of Mary-Ann is conceptually possible, the scenario at hand is conceptually impossible. Mary-Ann, due to a disturbance in her experience/belief transducer, is not able to recognize what color the red object in her vicinity is - that is certain. It is an open question, however, whether she might recognize what color the red object looks like to her. While I am inclined to say that Mary-Ann is likewise not able to recognize what color the red object looks like to her (because the disturbance in her experience/belief transducer impairs her capacity to determine what color the red object looks like to her), my opponent maintains that Mary-Ann can indeed recognize what color the red object looks like to her (because the disturbance in her experience/belief transducer does not affect her capacity to determine what color the red object looks like to her).
} 
experience as representing something as being red. Consequently, I have glossed the content of $\boldsymbol{I}$ as "I am currently having a visual experience as if there is something red in front of me". In both cases, the word "red" stands for the ordinary concept of redness as it refers to the color of external objects such as roses, blood, or ripe tomatoes. It is no wonder, then, that Mary-Ann's momentary inability to recognize a red object as red affects the epistemic status of $\boldsymbol{I}$ - for, under my reading, the content of $\boldsymbol{I}$ involves the ordinary concept of redness, that is, it involves the very same concept which Mary-Ann seems momentarily incapable of applying when it comes to the formation of perceptual beliefs about the color of objects in her vicinity. Note, however, that this is not the only approach that one may take with respect to the content of I. According to a widely held view, experiences are instantiations of phenomenal properties. In this sense, Mary-Ann's visual experience of red, $E$ for short, instantiates, inter alia, the phenomenal property of redness. Moreover, proponents of this view frequently emphasize that phenomenal properties should not be identified with ordinary properties. Phenomenal redness as it is instantiated by $E$, for example, is not the same as the color property that is represented by $E$ as being instantiated by some object in the external world, "external redness" for short. ${ }^{20}$ Consequently, in forming an introspective belief about $E$, Mary-Ann employs a concept that is different from the ordinary concept of redness in that it does not refer to external redness, but to phenomenal redness; that is, she has to employ what is commonly called a "phenomenal concept". Seen from this angle, Mary-Ann's momentary inability to recognize a red object as red seems to be irrelevant to the question of whether it is likely that $I$ is true-for, under the current reading, the content of $I$ does not involve the ordinary concept of redness at all. ${ }^{21}$

\footnotetext{
${ }^{20}$ See Chalmers 2003, 223.

${ }^{21}$ I owe this objection to an anonymous referee for this journal.
} 
In response to this, let me say that I consider the view that phenomenal properties are different from ordinary properties to be fundamentally mistaken. In my opinion, phenomenal properties of experiences, "qualia" as they are often called, are simply ordinary properties as they are represented to be instantiated by external objects. ${ }^{22}$ The phenomenal property of redness that is allegedly inherent to $E$, for example, is to be identified with the color property that $E$ represents some object in the external world to have, namely the color property of redness in its ordinary, external sense, as it is exemplified by roses, blood, or ripe tomatoes. If this identification is correct, then there is no need to assume the existence of extraordinary properties of experiences that might be picked out by extraordinary concepts. There simply are perfectly ordinary properties that can be picked out by perfectly ordinary concepts. Consequently, in forming an introspective belief about $E$, Mary-Ann has to fall back on the ordinary concept of redness, that is, on the very same concept that she seems momentarily incapable of applying when it comes to the formation of perceptual beliefs about the color of objects in her vicinity. Thus, the conditions under which $I$ is produced do not make it likely that it is true.

Let us turn now to another view on epistemic justification: consider the case of Mary-Ann in light of a deontological conception. According to this view, the question of whether a given belief is justified or not depends on whether the subject, in holding the belief in question, does not violate any epistemic obligation. ${ }^{23} \mathrm{~A}$ proponent of this view might argue that the unreliability of Mary-Ann's belief-forming process is detectable from an external perspective, but may not be detectable from Mary-Ann's perspective. It might be true, then, that the circumstances of its production are detrimental to the reliability of $I_{-}$but it is not at all true that Mary-Ann is violating any epistemic obligation in holding $\mathfrak{I}$.

\footnotetext{
${ }^{22}$ For reasons of space, I will not argue for this view here, but simply assume it to be true. Though not uncontentious, it is widely held in the literature. See Byrne 2001, Crane 2003, Dretske 1995, 65-95, Jackson 2003, and Tye 1995.

${ }^{23}$ See Alston 1989b, 86.
} 
But are we really prepared to concede this? Try to put yourself in Mary-Ann's shoes: even though you assent to the propositions (i) that you currently have the visual experience as if there is something red in front of you and (ii) that things currently are as you experience them to be, you withhold belief in the proposition (iii) that there is something red in front of you now. Thus, it seems that Mary-Ann is in a state of local irrationality.

However, one might object, this does not yet show that Mary-Ann is violating an epistemic obligation in holding $\mathbf{I}$. What can be said for sure is merely this: she is violating an epistemic obligation in withholding $\mathfrak{\wp}$. Even if it is not permissible for her to withhold $\mathfrak{\wp}$, it may be

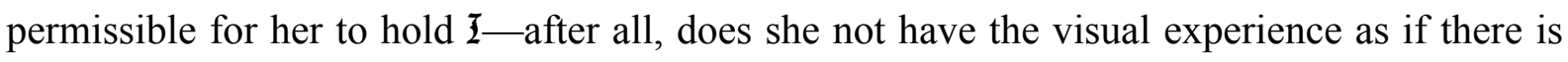
something red before her?

I do not find this reply very compelling. Let us assume, for the sake of the argument, that Mary-Ann is as epistemically responsible as she can be. Given this, Mary-Ann would certainly realize that she is in a state of local irrationality. Furthermore, she would try to give an account of this state. As far as I can see, there are three hypotheses available to her:

A: "Even though I have a visual experience of red and believe that things are as I experience them to be, my experience/belief transducer is malfunctioning and so does not produce a perceptual belief to the effect that there is something red in front of me."

B: "I have a visual experience of red and my experience/belief transducer is functioning properly. However, while I believe that I have the belief that things are as I experience them to be, I actually do not have this belief. Instead I have some belief to the effect that the way things are differs from the way I experience them to be, and it is because of this latter belief that my experience/belief transducer does not bring about a perceptual belief to the effect that there is something red in front of me." 
C: "While I believe that I have a visual experience of red, I actually do not have this experience. Since I believe that things are as I experience them to be, it is no wonder that my experience/belief transducer does not bring about a perceptual belief to the effect that there is something red in front of me."

Suppose that Mary-Ann assumes that $\mathrm{C}$ is the most accurate description of her current condition. Then it is obvious that she is violating an epistemic obligation in holding I-for there is an epistemic obligation not to believe the opposite of what one actually believes to be true.

Next, suppose that Mary-Ann believes that her current condition is best described by B. If she does, she will certainly think that she has made what Tyler Burge calls a "brute error", ${ }^{24} \mathrm{a}$ mistake through no fault of one's own-for Mary-Ann will not be able to find any introspective evidence that she holds some belief to the effect that the way things are differs from the way she experiences them to be, not even with all the will in the world. (Recall that, by hypothesis, Mary-Ann holds 23 .) As a result, she will feel estranged from the ongoings in her mind and distrust the findings of her introspective efforts in the same way as a man who believes that he is hallucinating distrusts the findings of his perceptual efforts. Since one is epistemically obliged to withhold any belief that arises from a source that one believes to be untrustworthy, Mary-Ann violates an epistemic obligation in holding $\mathbf{I}$.

Now let us suppose that Mary-Ann believes that A is correct. As we have already seen, believing that $\mathrm{A}$ amounts to believing that one is momentarily not able to recognize a red object as red, even under favorable perceptual conditions. Not being able to recognize a red object as red under favorable perceptual conditions, in turn, implies that one is not able to

\footnotetext{
${ }^{24}$ See Burge 1988, 657.
} 
recognize a visual experience of red as a visual experience that represents an object to be red. Since Mary-Ann, as we have assumed for the sake of argument, is as epistemically responsible as she can be, she will realize that this implication holds. Since it is an epistemic obligation to withhold any belief in matters of which one is ignorant, Mary-Ann, again, violates an epistemic obligation in holding $\mathbf{I}$.

Finally, let us have a look at $I$ under the presumption that the question of whether a given belief is justified or not depends on whether the subject, on sufficient reflection, is able to give a good reason for supposing that the belief in question is true. ${ }^{25}$ Is there any compelling reason that Mary-Ann could adduce to convince us (and herself) that $\boldsymbol{I}$ is true? Of course, she could say, "I just have a visual experience of red-period." But this reason is certainly not compelling, for we want to know how she could ever believe that she has the visual experience of red in view of the fact that, while she believes that things are as she experiences them to be, she does not believe that there is a red object in front of her. In order to be compelling, her reason should explain the obvious tension between $\mathbf{I}$, on the one hand, and the lack of a corresponding perceptual belief - given her background belief about perceptual conditions — on the other. What about the following, then: "My experience/belief transducer is malfunctioning. Even though I have a visual experience of red and believe that things are as I experience them to be, my experience/belief transducer suppresses any positive perceptual belief-I just can't help it!" But that won't do. As we have already seen, the fact that MaryAnn's experience/belief transducer is malfunctioning implies that Mary-Ann is momentarily not able to determine the color of objects in her environment, even under favorable perceptual conditions. If Mary-Ann is not able to determine the color of objects in her environment under favorable perceptual conditions-how will she know that she currently has a visual

\footnotetext{
${ }^{25}$ See Foley 1987, chap. 1.
} 
experience of red? It turns out, then, that even upon sufficient reflection, Mary-Ann would not be able to give a good reason for supposing that $I$ is true.

\section{Misunderstandings and objections}

In this section, I would like to address some potential misunderstandings of my argument and discuss several objections to it. But first, let me review the argument so far. I started by looking at a situation that is by no means unusual: a normal person, Mary-Ann, who is not only in a favorable perceptual condition, but who also holds a background belief to the effect that things are as they visually appear to be (23), holds both a correct perceptual belief about the color of an object in front of her $(\ngtr)$ and a correct introspective belief about her current visual experience $(\mathfrak{I})$. I suggested that, in this situation, $\mathfrak{I}$ depends for its justification on $\mathfrak{P}$. In order to reinforce this suggestion, I applied the immediacy test that I devised in section 2, that is, I considered a counterfactual situation in which—other things being equal—Mary-Ann does not hold $\mathfrak{P}$. It emerged that, in this case, Mary-Ann is not justified in holding $I$-no matter how the idea of epistemic justification might be construed. I concluded that $I$ is not immediate. Since truth-sufficiency is a variety of immediacy, one may also conclude that $I$ is not truth-sufficient either: the mere fact that Mary-Ann has a visual experience of red does not suffice to justify $\mathbf{I}$. It is also necessary that Mary-Ann hold $\mathfrak{\not}$. Generalizing, one may say that the justification of introspective beliefs about one's current visual experiences typically depends on those perceptual beliefs that one is rationally committed to hold relative to one's background beliefs about current perceptual conditions. ${ }^{26}$

\footnotetext{
${ }^{26}$ To be sure, there are some background beliefs that do not commit the subject to any perceptual beliefs at all. Suppose, for example, that, on the one hand, you believe that you currently have a visual experience as if there is
} 
Before I turn to the objections, let me forestall two possible misunderstandings. The first is that the argument that I put forward here is just a reincarnation of the so-called "level ascent" argument once formulated by Wilfrid Sellars. Sellars argues that the justification of a given introspective belief $B$ is dependent on a higher-order belief about the epistemic status of $B$. However, as contemporary foundationalists have pointed out, Sellars' argument is quite contestable. Insofar as there are good reasons not to accept Sellars' account of justification, then there are good reasons to reject the proposed argument about Mary-Ann. But this misconstrues my argument. Recall that I claim that the justification of Mary-Ann's introspective belief depends on a certain perceptual belief, namely, the belief "There is something red in front of me now". Perceptual beliefs like this are not higher-order beliefs in Sellars' sense. ${ }^{27}$

The second misunderstanding that I would like to address is the notion that my argumenteven though not identical to Sellars' "level ascent" argument-aims nevertheless at discrediting epistemological foundationalism. This is not true either. Assume, for the sake of argument, that I have shown (what I have in fact not) that no belief about one's current conscious experiences that are achieved by introspective means is immediate. This would not imply that foundationalism is false. It would only imply that some particular variety of foundationalism is false, namely, the traditional view that the foundation of empirical knowledge is constituted of beliefs about one's current conscious experiences. However, this does not mean that there is no foundation at all. In particular, it does not rule out the view that the foundation of empirical knowledge is constituted of perceptual beliefs about material objects in one's vicinity. The claim that beliefs about one's current conscious experiences are

something red in front of you and, on the other hand, you believe that you are a brain in a vat with systematically delusory experiences. In this case, you are not rationally committed to hold any perceptual belief about the color of objects in your vicinity. However, this does not mean that, in this situation, your introspective belief is immediate-for, as I will explain below, its justification depends on your background belief to the effect that you are a brain in a vat.

${ }^{27}$ Likewise, my argument has nothing to do with the "Master Argument for Coherentism", criticized by Pryor (2014). 
not immediate is perfectly compatible with the view that perceptual beliefs are immediate in that their justification does not stem from any other belief the subject might have, but from certain perceptual experiences the subject is undergoing - a position shared by many contemporary epistemologists with a foundationalist bias. ${ }^{28}$

One might object that, while the views in question may appear to be compatible, they do not match in spirit. In particular, it seems that one can argue that perceptual beliefs lack immediacy for similar reasons as those by which I have argued that introspective beliefs lack immediacy. Consider a counterfactual situation that differs from the actual situation of MaryAnn — in which, recall, she has a visual experience of red and holds $\mathfrak{I}, \mathfrak{Z}$, and $\mathfrak{Z} \bigoplus$ - only in that she does not hold $\mathfrak{I}$, that is, she does not introspectively believe that she currently has a visual experience of red. It seems, one might continue, that Mary-Ann's failure to recognize her visual experience of red as a visual experience of red implies that, momentarily, she cannot reliably apply the concept "red". So her perceptual belief $¥ \mathcal{O}$ is only true by accident and, thus, lacks justification. The upshot is that, in the same sense as $I$ depends for its justification on $\mathfrak{X}$, $\mathfrak{P}$ depends for its justification on $\mathbf{Z}$.

In my opinion, this result is somewhat counterintuitive. The crucial point is that there is a peculiar asymmetry between our criteria for reliable concept application: while we consider the failure to recognize a red material object as red—given favorable perceptual conditions and the lack of any background belief to the effect that the way things are differs from the way they appear to be - as detrimental to reliability, we consider failures to recognize a visual experience of red as red as tolerable in this respect. The reason is that visual experiences are accessible only from the first-person perspective and are thus beyond the view of others. Nobody except me can ever tell exactly which color is presented by a particular visual experience of mine. Accordingly, nobody can ever successfully demonstrate that I made a

\footnotetext{
${ }^{28}$ See Alston 1999, Pollock \& Cruz 1999, Pryor 2000, and Huemer 2001, 2007-to name but a few.
} 
mistake in applying or withholding a particular color word to my experience. In a sense, then, we enjoy a certain kind of fool's license with respect to our experiences: it does not matter much whether we have crazy beliefs about them or whether we lack beliefs about them others expect us to hold-so long as we are able to recognize red material objects as red (given favorable perceptual conditions and the lack of any background belief to the effect that the way things are differs from the way they appear to be), we are considered as reliable with respect to the application of the concept "red". Thus, Mary-Ann's failure to recognize her visual experience of red as a visual experience of red weighs relatively lightly compared to the failure to recognize a red material object as red. In particular, her failure to recognize her visual experience of red as a visual experience of red does not imply that she is momentarily not able to reliably apply the concept "red". Consequently, her perceptual belief $\mathfrak{P}$ is not deficient in any way.

It emerges that the two views in question - that introspective beliefs lack immediacy, on the one hand, and that perceptual beliefs are immediate, on the other-are not only compatible, but also match well in spirit. Therefore, my argument should not be understood as aimed against foundationalism. I do not intend to discredit the idea of immediacy as such-I only intend to discredit the idea that introspective beliefs about one's current visual experiences are immediate.

Now, let me turn to the real objections. The first objection is that I have not at all shown that $I$ depends for its justification on $\mathfrak{F}$. Instead, all I have shown is that, in the counterfactual situation, $I$ is defeated. According to this objection, what is going on in the counterfactual situation might be best described as follows: since Mary-Ann has a visual experience of red, she is at least prima facie justified in believing that she has a visual experience of red. However, this prima facie justification is undermined by the fact that, though she believes that things are as she experiences them to be, she has no idea about the color of the object in 
front of her. Thus, the reason why, in the counterfactual situation, Mary-Ann is not justified in holding $I$ is not that she lacks a belief without which $I$ would not have any justification at all. Rather, the reason is that she holds certain defeating beliefs-beliefs which undermine the prima facie justification she has by virtue of having the visual experience of red. ${ }^{29}$

Although this objection has initial appeal, it is not ultimately convincing. Consider a counterfactual situation-call it "super-counterfactual situation"- that differs from the counterfactual situation discussed in section 4 only in the fact that Mary-Ann lacks any beliefs whatsoever about the external world. Mary-Ann is not only totally clueless about the color of objects in her field of vision, but she is also clueless about the relation in which her appearances stand to reality. We are not even to unearth, from the depths of her belief system, a belief to the effect that she is deceived by an evil demon, is a brain in a vat, that the Matrix has her-or whatever. Thus, Mary-Ann does not hold any belief that could possibly play the role of a defeater. Accordingly, there is nothing in this situation that could possibly undermine the prima facie justification of $\boldsymbol{I}$ that — according to my opponent — is provided by Mary-Ann's visual experience of red. Consequently, my opponent would be committed to the claim that, in the super-counterfactual situation, Mary-Ann is justified in holding $\mathbf{I}$. However, this is highly implausible.

Certainly, there is a myriad of cases in which a subject is perfectly justified in believing that she has a visual experience of red, while, on the other hand, she forms no belief about the color of objects in her vicinity: she might believe that she is subject to an optical illusion, she might believe that she suffers from a hallucination, she might believe that she is deceived by an evil demon, she might believe that she is just a brain in a vat, and so on. However, notice that things in the super-counterfactual situation are different: by hypothesis, Mary-Ann has no such background belief at all. She is, as it were, absolutely silent about perceptual conditions.

\footnotetext{
${ }^{29}$ I am grateful to Thomas Grundmann for drawing this objection to my attention.
} 
Now, recall that it is conceptually necessary that a visual experience of red causes a perceptual belief to the effect that there is a red object in the vicinity, provided that (a) one's experience/belief transducer functions properly and (b) one lacks any belief to the effect that the way things are differs from the way one experiences them to be. Since, in the supercounterfactual situation, Mary-Ann satisfies condition (b) by hypothesis (recall that she lacks any belief whatsoever about the external world), she is thus in a similar situation as in the original counterfactual situation discussed in section 4: her experience/belief transducer is malfunctioning. Thus, all that has been said in section 4 about the question of whether $I$ is justified equally applies to the super-counterfactual situation as well.

Admittedly, this response may strike one as circular. In particular, it seems to be inappropriate to refer to what has been said in section 4 about the question whether $I$ is justified. However, the charge of circularity is unwarranted. It is due to a misconception of the dialectical situation. Note that the opponent does not deny that, in the original counterfactual situation discussed in section 4, I lacks justification. On the contrary, the opponent agrees on that point. The disagreement between the opponent and myself does not relate to the question whether $I$ is justified in the original counterfactual situation (we both say "no") but to the question in virtue of what $\mathbf{I}$ lacks justification: the opponent says "in virtue of the presence of some defeating beliefs", while I say "in virtue of the absence of an appropriate perceptual belief". The dialectical point of invoking the super-counterfactual situation, then, is to undermine the opponent's claim by making it plausible that the introspective belief that Mary-Ann holds in the original counterfactual situation would still be unjustified even if the alleged defeaters were removed. Thus, there is nothing dialectically illegitimate about my response. In particular, the reference to what has been said in section 4 about the question whether $I$ is justified is not inappropriate at all. 
Let me turn to the second objection. The second objection is that my argument glosses over the distinction between propositional and doxastic justification. To refresh our understanding of this distinction, let us revisit Hilary Kornblith's (1980) example of Alfred. Alfred justifiably believes that $p$ and justifiably believes that if $p$ then $q$. Furthermore, Alfred also believes that $q$. However, he believes $q$ not because $q$ follows from what he already justifiably believes, but because he likes the sound of some sentence that expresses the proposition that $q$. While Kornblith stoutly claims that "Alfred is not justified in believing that $q$ " (Kornblith 1980, 602), many epistemologists make a finer discrimination: they would deny that Alfred's belief that $q$ is doxastically justified, but they would admit that his belief is propositionally justified. One might say that being doxastically justified is a property of an actually held belief. Whether a belief is doxastically justified depends on the way it is held by the subject in question. In basing his belief that $q$ on his aesthetic preferences, for example, Alfred holds the belief that $q$ in a way that is epistemically irresponsible. This is why Alfred's belief lacks doxastic justification. In contrast, being propositionally justified is a property of a person. Whether a person is propositionally justified in holding a particular belief merely depends on the reasons possessed by the person in question - it is not even necessary that the target belief be actually held. In a sense, the only question that really counts here is: does the person have any good reason to hold the belief in question? Since Alfred justifiably believes that $p$ and justifiably believes that if $p$ then $q$, he does have a very good reason to hold the belief that $q$. This is why Alfred is propositionally justified in holding the belief that $q$.

Now, it might be said that, if my argument from Mary-Ann shows anything, it merely shows that, in the counterfactual situation, $\boldsymbol{I}$ is not doxastically justified. Admittedly, there is some oddness in the way $I$ is actually held by Mary-Ann. As is clear from the case of Alfred, however, it does not follow from the fact that a particular belief is not doxastically justified that it is not propositionally justified. It may be true, then, that in the actual situation, the 
doxastic justification of $I$ depends on $\mathfrak{P}$. However, this does not rule out that, in the actual situation, Mary-Ann's propositional justification to hold $I$ is independent from any other belief she holds. Thus, the argument from Mary-Ann does not show that, in the actual situation, the propositional justification that Mary-Ann has for holding $I$ is mediated by some other belief. If so, then my argument misses the mark, because the claim at issue is that having a particular visual experience suffices to propositionally justify a subject in holding an introspective belief to the effect that she has this experience. ${ }^{30}$

I am not really sure whether the claim at issue is about propositional, instead of doxastic, justification. However, for the sake of argument, let us grant this. Even then, I contend, the objection does not stand up under closer examination. If one admits that, in the counterfactual situation, $I$ is not doxastically justified, one must admit that, in the counterfactual situation, Mary-Ann is not propositionally justified in holding $\mathfrak{I}$ either. The reason is that doxastic justification can be explained in terms of propositional justification: doxastic justification is just propositional justification plus the basing relation, or so it seems. Thus, according to many epistemologists, the following conditional holds:

(P) Person $S$ is propositionally justified in holding belief $A$ in virtue of possessing reason $R \rightarrow$ If $S$ actually holds $A$ on the basis of $R, A$ is doxastically justified. ${ }^{31}$

If Mary-Ann was propositionally justified in holding $I$ in virtue of having the visual experience of red, then, according to $(\mathrm{P}), \mathbf{I}$ would also be doxastically justified — provided that she bases it on her current visual experience. Now, as the counterfactual situation is described

\footnotetext{
${ }^{30}$ I owe this objection to an anonymous referee.

${ }^{31}$ See Alston 1989b, 108; Feldman 2002, 46; Korcz 2000, 525-526; Kvanvig 2003, 8; Pollock and Cruz 1999 , 35-36; Swain 1979, 25. I owe these citations to Turri (2010), who is, at the same time, one of the most forceful critics of $(\mathrm{P})$. I will turn to Turri's alternative view below.
} 
in section 3 and 4, nothing prevents us from saying that Mary-Ann does base $\mathfrak{I}$ on her current visual experience. We are free to assume that she is aware of and focuses on her current experience - she wallows in phenomenal red, so to speak-while she forms 1 . Furthermore, we are free to assume that $I$ is caused by her experience. However, even under this redescription of the case, it appears that $I$ is not doxastically justified: recall that - despite holding a background belief to the effect that things currently are as they visually appear to be-Mary-Ann withholds belief in the proposition that there is a red object in front of her. As I explained at length in section 4 , this casts an epistemic shadow over $\mathbf{I}$. Thus, even on the supposition that, in the counterfactual situation, Mary-Ann bases I on her current visual experience, $\boldsymbol{I}$ is lacking doxastic justification. By $(\mathrm{P})$, it follows that Mary-Ann is not propositionally justified either.

Now, it might be objected that the redescribed case of Mary-Ann is just another example that shows that doxastic justification is not merely propositional justification plus the basing relation. More specifically, it seems that the counterfactual situation of Mary-Ann is somehow analogous to John Turri's (2010) case of Mr. Lacy: Mr. Lacy knows that $p$ and he knows that if $p$ then $q$. Furthermore, he believes that $q$ on the basis of the propositions $p$ and if $p$ then $q$. However, Mr. Lacy does not apply modus ponens to those propositions, but a different, and faulty, rule that reads, "From any two propositions, infer any proposition you like" ${ }^{32}$ Intuitively, Mr. Lacy's belief in $q$ is not doxastically justified, though he bases it on reasons in virtue of which he is propositionally justified in believing that q. In light of this and other counterexamples, Turri concludes that "doxastic justification cannot be understood simply as propositional justification plus basing." (Turri 2010, 319) Instead of (P), Turri thus suggests the following alternative:

\footnotetext{
${ }^{32}$ Compare Turri 2010, 317.
} 
(P*) Person $S$ is propositionally justified in holding belief $A$ in virtue of possessing reason $R \rightarrow S$ possesses at least one means of forming $A$ on the basis of $R$ such that, were $S$ to hold $A$ in one of those ways, $A$ would be doxastically justified. ${ }^{33}$

$\left(\mathrm{P}^{*}\right)$ goes well with the case of Mr. Lacy, because it does not force us to deny that Mr. Lacy is propositionally justified in believing that $q$. Though Mr. Lacy actually forms his belief that $q$ by applying a faulty inferential rule, it is reasonable to suppose that he does possess a means of forming the belief that $q$ on the basis of the propositions $p$ and if $p$ then $q$ that would yield a doxastically justified belief-for example, the means of applying modus ponens to those propositions.

Note, however, that the counterfactual situation of Mary-Ann is disanalogous to the case of Mr. Lacy in one crucial respect. In contrast to Mr. Lacy, Mary-Ann does not possess any alternative means of belief formation that would yield a doxastically justified belief to the effect that she currently has the visual experience of red. Recall that the fact that Mary-Ann does not accept the proposition that there is a red object in her vicinity implies that she is momentarily not able to recognize something red as red. Obviously, there is a disturbance in her color recognition system. Now, in order to form $I$ on the basis of her visual experience, Mary-Ann must rely on her color recognition system - there is just no alternative means that Mary-Ann could use to arrive at this belief. Every way that leads to I has to go through the narrow passage of Mary-Ann's color recognition system. However, as long as Mary-Ann's color recognition system is malfunctioning, any belief she forms by using it lacks doxastic justification. Thus, I think that, even according to $\left(\mathrm{P}^{*}\right)$, Mary-Ann is not propositionally justified in holding $I$ in the counterfactual situation.

\footnotetext{
${ }^{33}$ Compare Turri 2010, 320. In order to keep the structural analogy with (P), my formulation deviates from Turri's original formulation "(PJ)" in certain respects. However, it maintains the essence of Turri's proposal.
} 
To sum up: the objection that the argument from Mary-Ann glosses over the distinction between propositional and doxastic justification does not withstand scrutiny. Not only in light of the traditional view about the relationship between propositional and doxastic justification, but also in light of Turri's alternative view, it turns out that, in the counterfactual situation, I is neither doxastically nor propositionally justified. This, in turn, means that, in the actual situation, Mary-Ann's propositional justification for holding I is mediated by some other

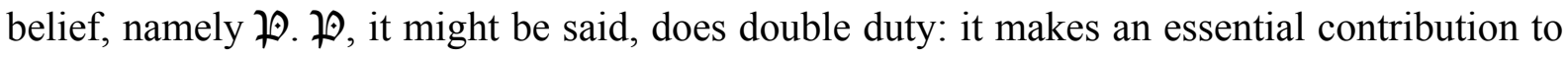
Mary-Ann's being propositionally justified in holding $I$ and it is necessary for the doxastic justification of $\boldsymbol{z}$.

Now, I come to the third objection. For sake of exposition, let me parse my argument from Mary-Ann into three steps. In the first step, I tried to show that $I$ does not pass the immediacy test that I suggested in section 2: there is another belief—namely, $\mathfrak{P}$ — such that, if Mary-Ann did not hold this belief, she would, other things being equal, not be justified in holding $\boldsymbol{I}$. In the second step, I concluded from the fact that $I$ does not pass the immediacy test that it is not immediate. In the third step, I concluded from the fact that $I$ is not immediate that it is not truth-sufficient either.

One might object here that, whatever may be the case with the first and the second step, the third step of my argument is definitely dubious since it presupposes the claim that, for all beliefs $x$, if $x$ is not immediate, $x$ is not truth-sufficient either. Restated in its contrapositive form, this claim amounts to the following:

(TSI) For all beliefs $x$ : if $x$ is truth-sufficient, $x$ is immediate. 
However, (TSI) is simply false: there may be beliefs that, albeit truth-sufficient, are not immediate. Thus, the third step of my argument is invalid-or so the objection goes. ${ }^{34}$

Why should (TSI) be false? Recall that the belief that $p$ is truth-sufficient if and only if the mere fact that $p$ constitutes justification for believing that $p$. Recall furthermore that the belief that $p$ is immediate if and only if the justification for believing that $p$ does not depend on any other belief the subject otherwise has. Now, suppose that you have the introspective belief that you believe that $p$. In addition, suppose for the sake of argument that this introspective belief is truth-sufficient, that is, the mere fact that you believe that $p$ constitutes justification for your introspective belief that you believe that $p$. In this case, your introspective belief is not immediate - for your justification of this belief does depend on another belief, namely, the belief that $p$. If you did not hold the belief that $p$, you would, other things being equal, not be justified in holding the introspective belief that you believe that $p$.

Thus, one might say that, contrary to what I have suggested, truth-sufficiency is not a variety of immediacy at all: as the example shows, there might be beliefs that, albeit not immediate, are truth-sufficient. So, even if my argument shows that $I$ is not immediate, one may not conclude that $\boldsymbol{I}$ is not truth-sufficient.

In my view, this objection is partially right in that (TSI) is false. But the fact that (TSI) is false does not pose a serious threat to my argument-for the move from " $I$ is not immediate" to "I is not truth-sufficient" can be justified without an appeal to (TSI).

I concede that there might be beliefs that are truth-sufficient but not immediate. However, I deny that beliefs about one's own visual experiences are among them. To see the point, try to imagine a belief to the effect that one has such-and-such visual experience that lacks immediacy, but possesses truth-sufficiency. To lack immediacy means that there is another belief $B$ such that, if one did not have it, one would not be justified in believing that one has

\footnotetext{
${ }^{34}$ I owe this objection to an anonymous referee.
} 
such-and-such visual experience. In short, lacking immediacy means that there is another belief $B$ that makes an essential contribution to the justification of the belief in question. To possess truth-sufficiency, in turn, means that the mere fact that one has such-and-such visual experience suffices to justify the belief that one has such-and-such visual experience. Now, you cannot have it both ways. If there is another belief $B$ that makes an essential contribution to the justification of the belief that one has such-and-such visual experience, then the mere fact that one has such-and-such visual experience cannot be sufficient for being justified in believing that one has such-and-such visual experience-if it were sufficient, the contribution of belief $B$ would not be essential. If, in turn, the mere fact that one has such-and-such visual experience suffices to justify the belief that one has such-and-such visual experience, then there cannot be another belief $B$ that makes an essential contribution to the justification of the belief that one has such-and-such visual experience-if there were such a belief $B$, the mere fact that one has such-and-such visual experience would not be sufficient for justification.

Presumably, my antagonist will not be satisfied. She might point out that, in contrast to what I suggest, it is very easy to imagine an introspective belief about one's current visual experience that is, albeit not immediate, truth-sufficient. Suppose for the sake of argument that $S$ 's belief that she has a visual experience of type $X$ is truth-sufficient; that is, $S$ 's belief that she has a visual experience of type $X$ is justified just in virtue of the fact that $S$ has a visual experience of type $X$. Suppose furthermore that $S$ 's visual experience of type $X$ is caused by another belief that $S$ holds, say, the belief that $q$. (This assumption might seem odd in empirical respects, but, of course, it is not conceptually incoherent.) It seems, therefore, that, although $S$ 's introspective belief about her own visual experience is truth-sufficient (as it is by hypothesis), there is indeed a different belief $B$ (namely, the belief that $q$ ) such that, if $S$ did not hold it, she would not be justified in believing that she has the visual experience of type $X$-for if $S$ did not believe that $q$, she would not have the visual experience of type $X$ 
either. If $S$ did not have the visual experience of type $X$, in turn, her belief that she has the visual experience of type $X$ would not be justified. Thus, even though $S$ 's belief that she has the visual experience of type $X$ is truth-sufficient, it turns out to be not immediate.

In my view, this argument fails since it does not take into account the ceteris paribus clause that is essential to the immediacy test that I suggested in section 2. As I said before, a proper application of this test requires us to envisage a counterfactual situation in which the belief that is supposed to have a bearing on the target belief is absent, while other things remain constant. For the case at hand, this means that, in order to determine whether $S$ 's belief that she has the visual experience of type $X$ depends for its justification on the belief that $q$ (and therefore is not immediate), one has to imagine a situation in which (i) $S$ believes that she has the visual experience of type $X$, (ii) $S$ has the visual experience of type $X$, and (iii) $S$ does not believe that $q$-and then ask, with respect to this situation, whether $S$ 's belief that she has the visual experience of type $X$ is still justified. If you do this, you get the following result: even if $S$ did not hold the belief that $q$, she would still be justified in believing that she has the visual experience of type $X$-for, though lacking the belief that $q, S$ still has the visual experience of type $X$. Of course, this may not demonstrate in one stroke that $S$ 's introspective belief is immediate, but it does demonstrate that $S$ 's belief that $q$ has no bearing on $S$ 's introspective belief. Thus, the case envisaged by my antagonist does not present an example of an introspective belief about one's current visual experiences that is truth-sufficient but not immediate.

The upshot is that the conditional "If a belief is truth-sufficient, it is immediate as well" is viable as long as one restricts its scope to introspective beliefs about one's current visual experiences. Since my paper makes a claim about these beliefs only — and not a claim about, say, introspective beliefs about one's own beliefs - the third step of my argument is tenable: if 
a given introspective belief about one's current visual experiences does not pass the immediacy test, then one may legitimately conclude that it is not truth-sufficient either.

\section{Conclusion}

In this paper, I have attempted to show that introspective beliefs about one's own current visual experiences are not immediate in the sense that what justifies these beliefs does not include other beliefs that the subject in question might possess. Instead, for every justified introspective belief about one's own current visual experience $A$, there is always some other belief $B$ such that, if the subject did not have $B$, she would not be justified in holding $A$. I have concluded from this that introspective beliefs about one's own current visual experiences are not truth-sufficient either: the mere fact that the subject has a particular visual experience does not suffice to justify her belief that she has this experience.

\section{Acknowledgements}

This paper originated in a talk given at a workshop on the topic of "First-Person Authority" at the University of Duisburg-Essen in March 2014. I am indebted to the participants, in particular Yuliya Fadeeva, Thomas Grundmann, Frank Hofmann, Andreas Kemmerling, Dirk Koppelberg, Michael Pauen, Kevin Reuter, Stefan Roski, and Thomas Spitzley, for many helpful suggestions and thought-provoking questions. Thomas Spitzley deserves special thanks for his support and encouragement during my time as a research fellow at the University of Duisburg-Essen. Furthermore, I am grateful to Xenia Hladin, Bernd Lahno, Raphael van Riel, Thorsten Sander, Tobias Steinig, and Christiana Werner, each of whom read a previous draft of this paper and provided extremely valuable comments. I would also like to thank several anonymous referees who greatly helped me to clarify my argument. 
Work on this paper was supported by research grants BA 2269/2-1 and BA 2269/2-2 from the German Research Foundation (DFG).

\section{References}

Alston, William 1971. "Varieties of Privileged Access.” American Philosophical Quarterly 8, $223-241$.

Alston, William 1976. "Self-Warrant: A Neglected Form of Privileged Access." American Philosophical Quarterly 13, 257-272.

Alston, William 1989a. "What's Wrong with Immediate Knowledge?” In: William Alston, Epistemic Justification: Essays in the Theory of Knowledge, Ithaca, NY: Cornell University Press, 57-78.

Alston, William 1989b. “Concepts of Epistemic Justification.” In: William Alston, Epistemic Justification: Essays in the Theory of Knowledge, Ithaca, NY: Cornell University Press, 81114.

Alston, William 1996. A Realist Conception of Truth. Ithaca, NY: Cornell University Press.

Alston, William 1999. "Perceptual Knowledge.” In: The Blackwell Guide to Epistemology, edited by John Greco and Ernest Sosa, Oxford: Blackwell, 223-242.

Armstrong, David 1968. A Materialist Theory of the Mind. London: Routledge and Kegan Paul.

Ayer, Alfred J. 1963. "Privacy.” In: Alfred J. Ayer, The Concept of a Person and Other Essays, New York: St. Martin's Press, 52-81.

Burge, Tyler 1988. “Individualism and Self-Knowledge.” Journal of Philosophy 85, 649-663. Byrne, Alex 2001. “Intentionalism Defended.” Philosophical Review 110, 199-240.

Byrne, Alex 2005. “Introspection.” Philosophical Topics 33, 79-104. 
Byrne, Alex 2011a. "Knowing What I am Thinking.” In: Self-Knowledge, edited by Anthony Hatzimoysis, Oxford: Oxford University Press, 105-124.

Byrne, Alex 2011b. "Transparency, Belief, Intention." Proceedings of the Aristotelian Society, Supplementary Volume 85, 201-221.

Byrne, Alex 2012. "Knowing What I Want." In: Consciousness and the Self: New Essays, edited by JeeLoo Lui and John Perry, Cambridge: Cambridge University Press, 165-183.

Chalmers, David 2003. "The Content and Epistemology of Phenomenal Belief." In: Consciousness: New Philosophical Perspectives, edited by Aleksandar Jokic and Quentin Smith, Oxford: Clarendon, 220-272.

Crane, Tim 2003. "The Intentional Structure of Consciousness.” In: Consciousness: New Philosophical Perspectives, edited by Aleksandar Jokic and Quentin Smith, Oxford: Oxford University Press, 33-56.

Dretske, Fred 1995. Naturalizing the Mind. Cambridge, MA: MIT Press.

Evans, Gareth 1982. The Varieties of Reference. Oxford: Oxford University Press.

Feldman, Richard 2002. Epistemology. Upper Saddle River, NJ: Prentice Hall.

Fernández, Jordi 2003. "Privileged Access Naturalized." The Philosophical Quarterly 53, $352-372$.

Fernández, Jordi 2013. Transparent Minds: A Study of Self-knowledge. Oxford: Oxford University Press.

Foley, Richard 1987. The Theory of Epistemic Rationality. Cambridge, MA: Harvard University Press.

Gallois, André 1996. The World Without, the Mind Within: An Essay on First-person Authority. Cambridge: Cambridge University Press.

Gordon, Robert M. 1996. “Radical' Simulationism.” In: Theories of Theories of Mind, edited by Peter Carruthers and Peter K. Smith, Cambridge: Cambridge University Press, 11-21. 
Penultimate draft. Please cite published version: doi10.1163/18756735-000022.

Huemer, Michael 2001. Skepticism and the Veil of Perception. Lanham: Rowman and Littlefield.

Huemer, Michael 2007. "Compassionate Phenomenal Conservatism." Philosophy and Phenomenological Research 74, 30-55.

Hume, David 1978. A Treatise of Human Nature, edited by Peter H. Nidditch, Oxford: Clarendon Press.

Jackson, Frank 2003. "Mind and Illusion.” Royal Institute of Philosophy Supplement 53, 251271.

Korcz, Keith 2000. "The Causal-Doxastic Theory of the Basing Relation." Canadian Journal of Philosophy 30, 525-550.

Kornblith, Hilary 1980. "Beyond Foundationalism and the Coherence Theory." The Journal of Philosophy 77, 597-612.

Kvanvig, Jonathan 2003. "Propositionalism and the Perspectival Character of Justification." American Philosophical Quarterly 40, 3-18.

Moran, Richard 2001. Authority and Estrangement. Princeton: Princeton University Press.

Neta, Ram 2011. "The Nature and Reach of Privileged Access.” In: Self-Knowledge, edited by Anthony Hatzimoysis, Oxford: Oxford University Press, 9-32.

Pollock, John L. and Cruz, Joseph 1999. Contemporary Theories of Knowledge. Lanham: Rowman \& Littlefield.

Pryor, James 2000. "The Skeptic and the Dogmatist.” Noûs 34, 517-549.

Pryor, James 2014. "There Is Immediate Justification." In: Contemporary Debates in Epistemology, edited by Matthias Steup, John Turri, and Ernest Sosa, Oxford: Blackwell, $202-222$.

Sheridan, Gregory 1969. "The Electroencephalogram Argument against Incorrigibility." American Philosophical Quarterly 6, 62-70. 
Penultimate draft. Please cite published version: doi10.1163/18756735-000022.

Smithies, Declan 2012. "A Simple Theory of Introspection." In: Introspection and Consciousness, edited by Declan Smithies and Daniel Stoljar, Oxford: Oxford University Press, 259-293.

Swain, Marshall 1979. "Justification and the Basis of Belief." In: Justification and Knowledge, edited by George Pappas, Dordrecht: Reidel, 25-49.

Turri, John 2010. “On the Relationship between Propositional and Doxastic Justification.” Philosophy and Phenomenological Research 80, 312-326.

Tye, Michael 1995. Ten Problems of Consciousness. Cambridge, MA: MIT Press. 